九州大学学術情報リポジトリ

Kyushu University Institutional Repository

\title{
Development of an Intelligent Robot for an Agricultural Production Ecosystem (V) : Experiments on Predation of Paddy by Golden Apple Snails
}

\section{Luna Maldonado, Alejandro Isabel}

Laboratory of Agricultural Ecology, Division of Agricultural Ecology, Department of Plant Resources, Faculty of Agriculture, Kyushu University

Yamaguchi, Yusuke

Laboratory of Agricultural Ecology, Division of Agricultural Ecology, Department of Plant Resources, Faculty of Agriculture, Kyushu University

Nakaji, Ke i

Laboratory of Agricultural Ecology, Division of Agricultural Ecology, Department of Plant Resources, Faculty of Agriculture, Kyushu University

https://doi.org/10.5109/14066

出版情報: 九州大学大学院農学研究院紀要. 54 (1)，pp.235-239，2009-02-27. Faculty of Agriculture, Kyushu University

バージョン:

権利関係 : 


\title{
Development of an Intelligent Robot for an Agricultural Production Ecosystem (V) - Experiments on Predation of Paddy by Golden Apple Snails -
}

\author{
Alejandro Isabel LUNA MALDONADO ${ }^{1}$, Yusuke YAMAGUCHI ${ }^{1}$ \\ and Kei NAKAJI* \\ Laboratory of Agricultural Ecology, Division of Agricultural Ecology, Department of \\ Plant Resources, Faculty of Agriculture, Kyushu University, \\ Fukuoka 811-2307, Japan \\ (Received November 14, 2008 and accepted December 5, 2008)
}

\begin{abstract}
Experiments were carried out in small lots at Kyushu University Farm in order to measure the parameters of predation and get models of the biomass of rice plants and weeds and population of golden apple snails over different phases of season of rice production ecosystem.
\end{abstract}

\section{INTRODUCTION}

The activity of snails is based on water temperature and water depth. The growth of rice plants depends on the predation by snails and the competition against weeds. The predation of rice plants and weeds by snails involves parameters such as, the shell height and weight of snails, the attack efficiency of snails, reproduction rate of snails, mortality and intrinsic rates of snails and predation rate of superior plants by snails. In this study, we will establish several experiments in order to obtain the parameters of predation and model the populations of snails and biomass of rice plants and weeds during the rice crop season at Kyushu University Farm.

\section{MATERIALS AND METHODS}

\section{Experiments about the predation of plants and weeds by golden apple snails}

In order to estimate the parameters of predation considering the interaction among golden apple snails, rice plants, and weeds, 16 experimental plots $(1 \times 3 \mathrm{~m})$ were set up for each treatment at water depth $5 \mathrm{~cm}$ of height in Kyushu University Farm on June 23th and $28^{\text {th }}$. The treatments consisted of 8 plots for mortality and birth rate with only four snails: 2 female snails averaging $34.3 \mathrm{~mm}$ of shell height and $9.52 \mathrm{~g}$ of weight and 2 males averaging $34 \mathrm{~mm}$ of shell height and $8.82 \mathrm{~g}$. In addition, 2 lots for consumption of weeds by only 0 snails, 2 plots for consumption of weeds by only 1 snails, 2 plots for consumption of weeds by only 2 snails and 2 plots for consumption of weeds by only 3 snails were set up.

\section{Measuring populations, shell height and weights of snails}

We measured the amount, weights and shell heights of snails inside of all lots for $168.2 \mathrm{~m}^{2}$ in these experi-

\footnotetext{
Laboratory of Agricultural Ecology, Division of Agricultural Ecology, Graduate School of Bioresources and Bioenvironmental Sciences, Kyushu University

* Corresponding author (E-mail: knkjfam@mbox.nc.kyushu-u. ac.jp
}

ments and another experiments on July 8th considering snails have at least a shell height from $20 \mathrm{~mm}$ to $40 \mathrm{~mm}$ because in this range of shell heights the snails are more destructive (Joshi et al., 2002 and Luna and Nakaji, 2008, Luna et al., 2008a, Luna et al., 2008b). We did again a sampling for snails over $120 \mathrm{~m}^{2}$ on July 11th of 2008 but now we also classified them by gender.

We modeled the biomass ate by snails using the sigmoidal form of Viggs and Burley (Viggs et al., 1991), which considers the temperature response function and we get the predation rate by using the Richards equation (Richard, 1959) as follows,

$$
P_{r}=W_{d} A_{p}\left(\frac{C_{\max }}{1+e^{-\alpha_{t}\left(T-T_{\mathrm{min}}\right)}}\right)
$$

Where, $P_{r}$ : predation rate of plants (rice plants or weeds) in the paddy, $W_{d}=$ snail activity coefficient according to the water depth, $A_{p}=$ snails density or abundance, $C_{\max }=$ maximum consumption of rice plants by snails per day, $e=2.718, \alpha_{\mathrm{t}}=$ a slope parameter, $T$ =water temperature (Celsius degrees) and $T_{\text {inf }}=$ water temperature (Celsius degrees) in the inflection point of the curve.

The $W_{d}$ is calculated considering a shallow water depth of $10-20 \mathrm{~mm}$ should be maintained to immobilize snails and prevent them from attacking rice plants. We considered that the snails at $T_{i n f}$ of 12 Celsius degrees will start hardly to move around the paddy.

\section{Measuring the water temperatures in paddy and activity of snail}

We measured the water temperatures in paddy from day of transplanting (June 20th) until day which rice plants have reached $400 \mathrm{~mm}$ of height (July 20th). We also conducted experiments in the laboratory on November 4th and 5th, in order to know the activity of snail based in the speed of snail at different temperatures. We used 4 snails whose shell heights were between 22 to $25 \mathrm{~mm}$. The water depth was $30 \mathrm{~mm}$. The speed of snails was measured in $\mathrm{mm} / \mathrm{s}$.

\section{RESULTS}

The severe predation of rice plants by snails occurs 
in early growth of paddy. After transplanting on June 20 th, the snails voraciously consumed rice plants. The snail ate 8 rice plants of $140 \mathrm{~mm}$ of height $(0.30 \mathrm{~g}$ of dried biomass) per day when water depth was $50 \mathrm{~mm}$ of height where as the snail ate 2 rice plants of $190 \mathrm{~mm}$ of height per day when water depth was $20 \mathrm{~mm}$ of height.

The number of snails, taking in account only snails with shell height $\geq 20 \mathrm{~mm}$, after transplanting was 17 only per $168.2 \mathrm{~m}^{2}$.

Table 1 shows the mortality rate of snails. We found that only 1 snail was died of a total of 12 snails ( $\geq 20 \mathrm{~mm}$ of shell height) distributed in 6 plots on June 23th. On June 28 we found that of a total of 12 snails ( $\geq 20 \mathrm{~mm}$ of shell height) distributed in 6 plots only one was found died.

Table 2 shows the number of eggs laid by female snails ( $\geq 20 \mathrm{~mm}$ of shell height) on June 29th. They were numerous; however the hatching of them takes 8-12 days (Teo, 2004) and then the snails require 25 days to reach $20 \mathrm{~mm}$, of height, therefore those snails are not harmful for rice plants between $120 \mathrm{~mm}$ to $400 \mathrm{~mm}$ of height (Luna and Nakaji, 2008).

Figure 1 shows the distribution histogram for shell heights and weights of snails handpicked up on July 8th. The population of snails was 266 ( $\geq 20 \mathrm{~mm}$ of shell height) per $168.2 \mathrm{~m}^{2}$. The mean shell height and mean weight were $28.45 \pm 3.60 \mathrm{~mm}$ and $5.71 \pm 2.10 \mathrm{~g}$, respectively.

Figure 2 shows the distribution histogram for shell heights and weights of snails sorted by gender and handpicked up of an area of $120 \mathrm{~m}^{2}$ on July 11th. The mean shell heights and mean weight for females ( $\geq 20 \mathrm{~mm}$ of shell height) ( $\geq 20 \mathrm{~mm}$ of shell height) and males ( $\geq 20 \mathrm{~mm}$ of shell height) were $28.44 \pm 3.40 \mathrm{~mm}$ and $27.31 \pm 3.20 \mathrm{~mm}$, respectively. The mean weights and mean weight for females ( $\geq 20 \mathrm{~mm}$ of shell height) and males ( $\geq 20 \mathrm{~mm}$ of shell height) were $4.87 \pm 1.61 \mathrm{~g}$ and $4.6 \pm 1.57 \mathrm{~g}$ respectively. The number of females was 104 whereas the number of males was 110 .

Figure 3 shows the distribution histograms of female snails (a), male snails (b) and total number of snails found in 16 lots of 3 square meters on July 11th of 2008. The total number of snails ( $\geq 20 \mathrm{~mm}$ of shell height) found in those 16 lots was 164 (number of females and males were 95 and 69, respectively).

Table 3 shows the shell height and weights of snails ( $\geq 20 \mathrm{~mm}$ of shell height) sorted by gender. The shell heights of male and females were increased $2.09 \mathrm{~mm}$ and $2.17 \mathrm{~mm}$, respectively after three days. The weights of male and females were increased $0.66 \mathrm{~g}$ and $0.66 \mathrm{~g}$, respectively after three days.
Table 1. Mortality rate of golden apple snails ( $\geq 20 \mathrm{~mm}$ of shell height) on June 23th, and June 28th of 2008

\begin{tabular}{cc}
\hline Number of snails and date & Mortality rate \\
\hline a. 12 snails distributed in 8 plots on June 23th. & 0.083 \\
b. 12 snails distributed in 8 plots on July 28th. & 0.083 \\
\hline
\end{tabular}

Table 2. Eggs laid by female snails ( $\geq 20 \mathrm{~mm}$ of shell height) on June 29th of 2008.

\begin{tabular}{ccc}
\hline Lot & Number of Clusters & Eggs \\
\hline 1 & 2 & 378 \\
2 & 4 & 756 \\
3 & 3 & 567 \\
\hline
\end{tabular}

* Each plot had an area of 3 square meters.

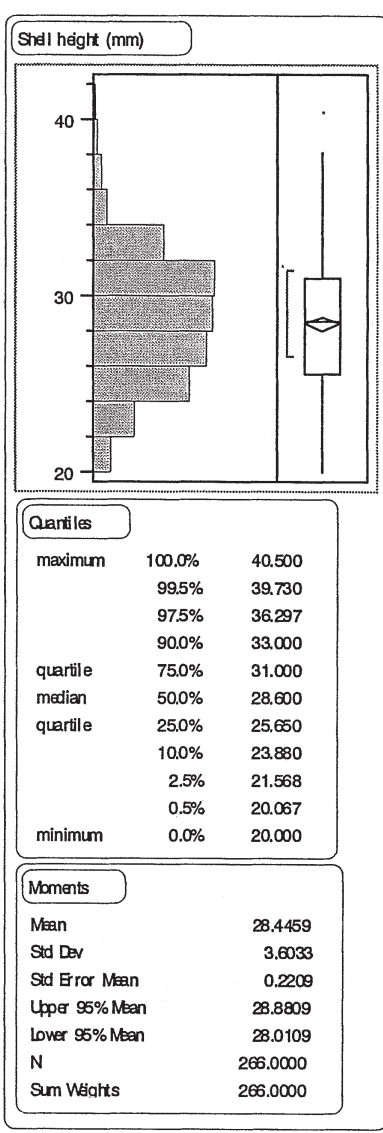

(a)

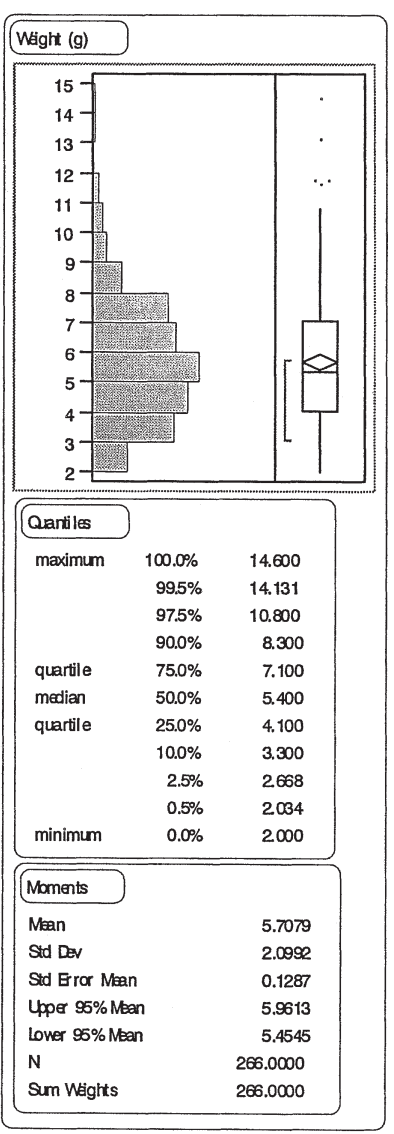

(b)
Fig. 1. Spread of distribution of shell height (a) and weight (b) of snails ( $\geq 20 \mathrm{~mm}$ of shell height) found in an area of $168.2 \mathrm{~m}^{2}$ on July 8th, 2008.

Table 3. Shell height and weights of snails ( $\geq 20 \mathrm{~mm}$ of shell height) sorted by gender on July 8th, and July $11^{\text {th }}$ of 2008

\begin{tabular}{ccccccc}
\hline \multirow{2}{*}{ Date } & \multicolumn{2}{c}{ Shell height $(\mathrm{mm})$} & & \multicolumn{2}{c}{ Weight $(\mathrm{g})$} \\
\cline { 2 - 3 } \cline { 5 - 6 } & \multicolumn{2}{c}{ Male } & Female & & Male & Female \\
\hline July 8th, 2008 & $23.20 \pm 2.80$ & $23.35 \pm 3.22$ & & $3.20 \pm 1.23$ & $3.24 \pm 1.65$ \\
July 11th, 2008 & $25.29 \pm 3.63$ & $25.52 \pm 3.83$ & & $3.86 \pm 1.82$ & $3.90 \pm 1.81$ \\
\hline
\end{tabular}




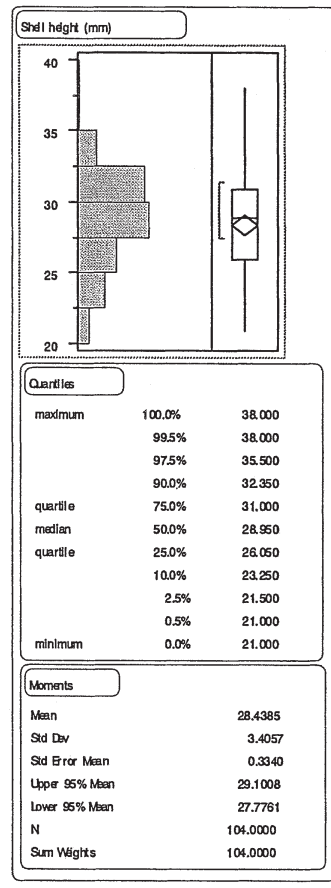

(a)

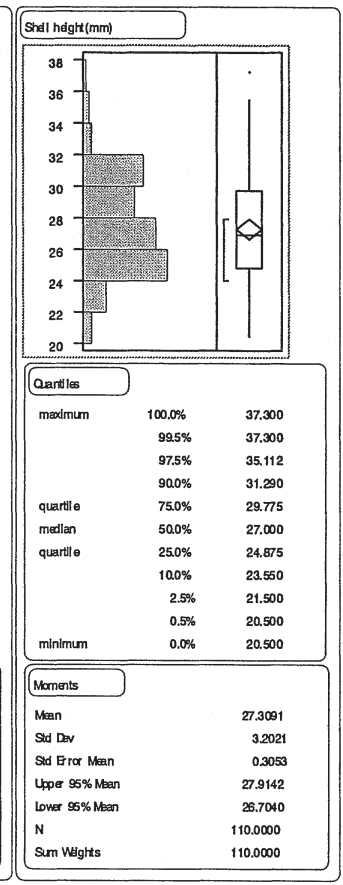

(b)

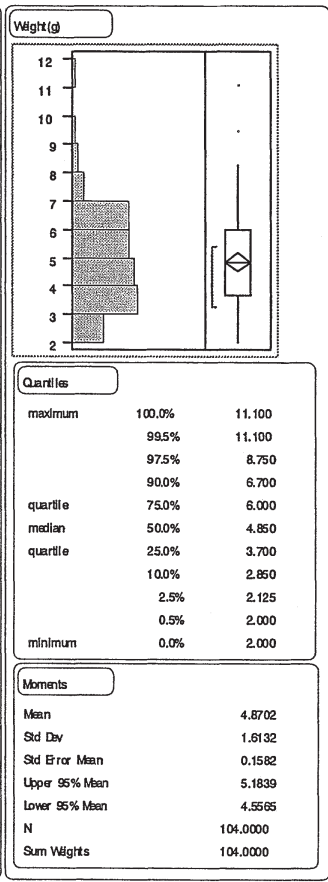

(c)

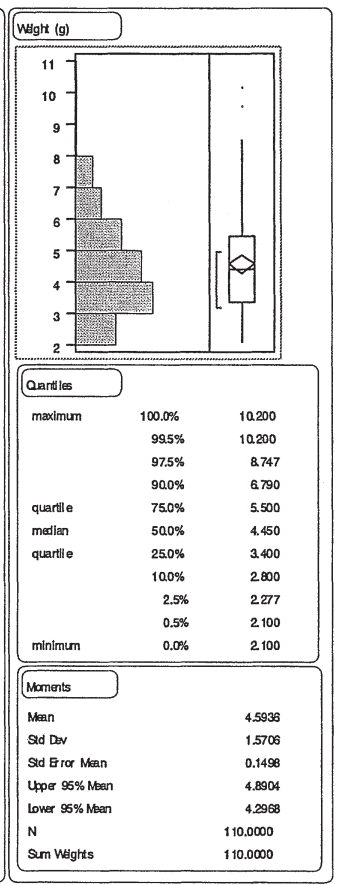

(d)

Fig. 2. Distribution of shell height of female snails (a) and shell height of male snails ( $\geq 20 \mathrm{~mm}$ of shell height) hand picked up in an area of $16.8 \mathrm{~m}^{2}$ on July 11th, 2008 and distribution of weight of female snails (a) and weight of male snails ( $\geq 20 \mathrm{~mm}$ of shell height) hand picked up in an area of $120 \mathrm{~m}^{2}$ on July 11 th, 2008.

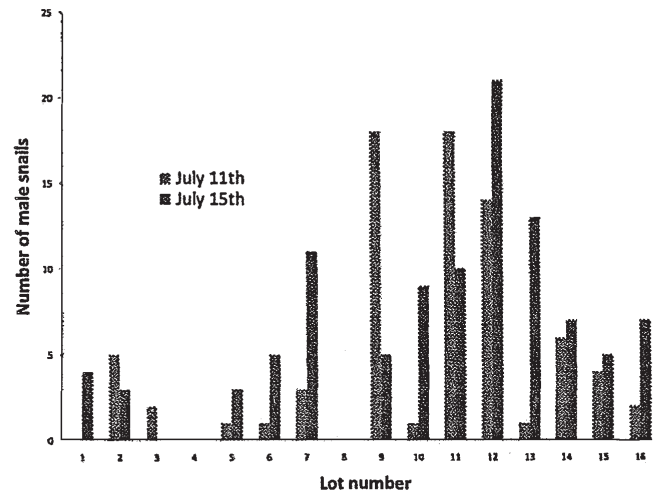

(a)

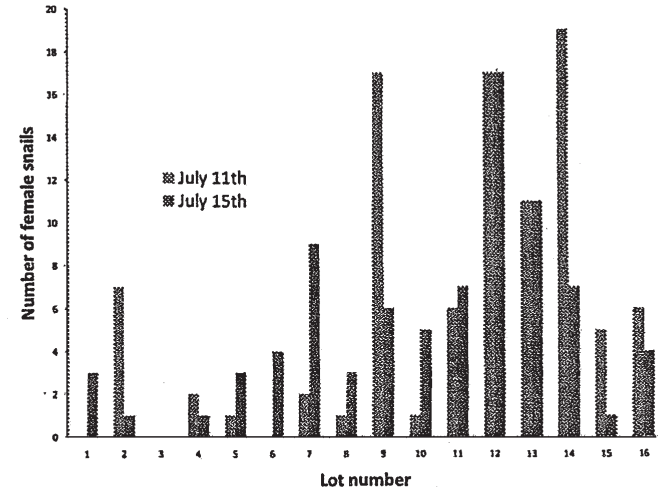

(b)

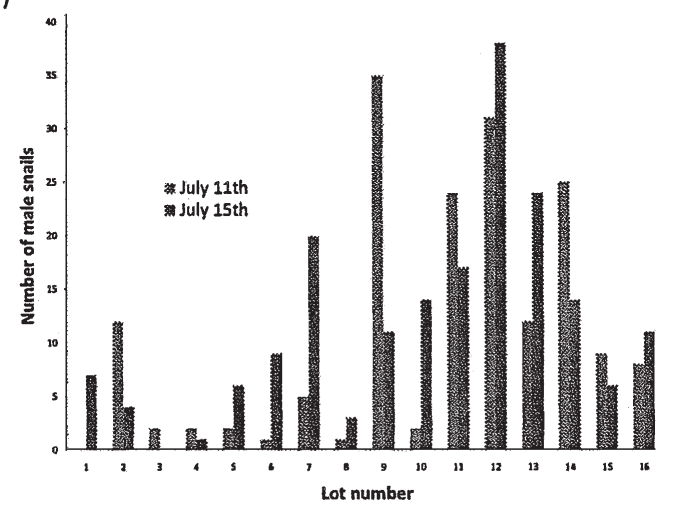

(c)

Fig. 3. Distribution per lot ( 3 square meters) of the populations of female snails ( $\geq 20$ mmof shell height) (a), male snails ( $\geq 20 \mathrm{~mm}$ of shell height) (b) and total number of snails ( $\geq 20 \mathrm{~mm}$ of shell height) at July 11th of 2008 . 


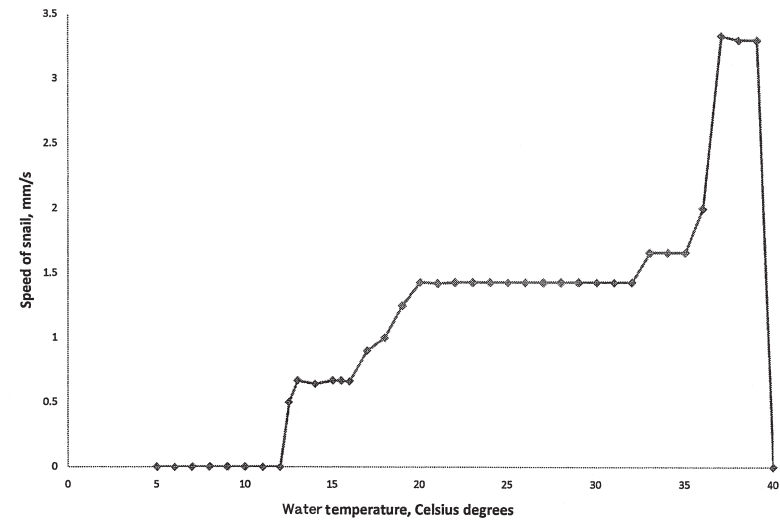

Fig. 4. Speed of snail (shell height of $22 \sim 25 \mathrm{~mm}$ ) related to the water temperature and water depth of $30 \mathrm{~mm}$, November 4th and 5th of 2008

Figure 4 shows that snails started to move in water at 12 Celsius degrees at $0.5 \mathrm{~mm} / \mathrm{s}$ and they could be active at 39 Celsius degrees. Water temperatures above 30 Celsius degrees have a harmful effect on snails (Teo, 2004). In our experiment when the temperatures were 20 to 32 Celsius degrees, the speed of snails was $1.43 \mathrm{~mm} / \mathrm{s}$. On the other hand at water temperatures between 33-38 Celsius degrees, the speed of the snail was 1.6 to $3.3 \mathrm{~mm} / \mathrm{s}$ and the snails had desperation. When water temperature was 39 Celsius degrees, the snails had panic and tried to leave the container. On the other, at when water temperature reached 40 Celsius degrees the snails stopped moving.

Figure 5 shows the mean temperatures from day of transplanting until day which rice plants has reached $400 \mathrm{~mm}$ of height (July 20th). The temperature has an effect on the predation of rice plants by snails.

Figure 6 shows the dried biomass of rice plants (g-d.w.) consumed by a snail per day in function to the temperature. We used the sigmoidal form of Viggs and

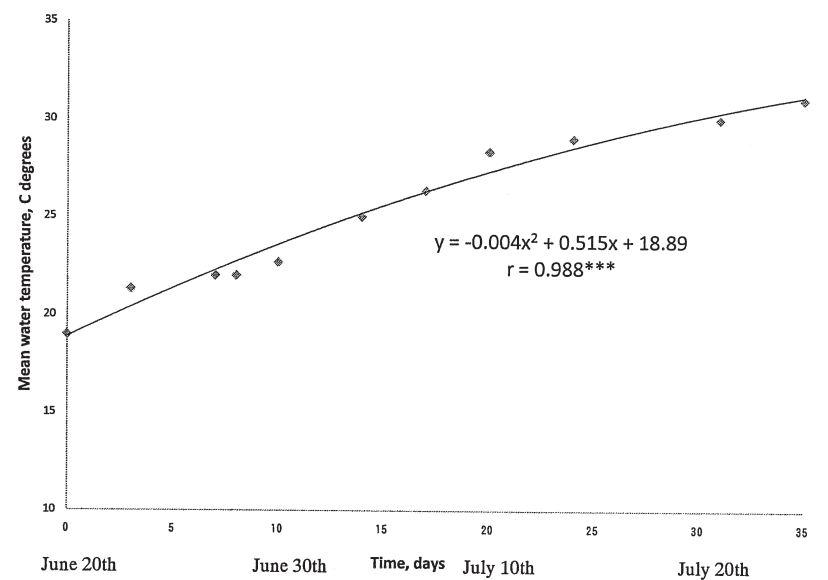

Fig. 5. Mean water temperatures at 7:00 pm in paddy field from transplanting day (June 20th) until day 35 (July 21th) of 2008.
Burley to obtain temperature response function and we got the curve of predation rate by using the equation of Richards and it was significant with a correlation coefficient $\mathrm{r}=0.999 * * *$ at $99 \%$ of confidence level. The proposed coefficient of depth water rate was 0.7. A snail of $34 \mathrm{~mm}$ of shell height and $9 \mathrm{~g}$ of weight consumed 0.3 g-d.w. per day. The density of snails observed per square meter on June 20th, July 18th and July 21th were 1,16 , and 39 snails respectively.

Figure 7 shows the population of snails ( $\geq 20 \mathrm{~mm}$ of shell height) predicted by the equation of Richards was significant with a correlation coefficient $r=0.999 * * * a t$ 99\% of confidence level. Figure 8 shows curves of biomass of rice plants, Tamagayatsuri and non superior weeds per square meter. The biomass of rice plants Tamagayatsuri and non superior weeds were predicted by Verhulst logistic model (Luna et al., 2008c). The data of density of snails ( $\geq 20 \mathrm{~mm}$ of shell height) per square meter was fitted by Richards's equation in paddy. Rice plants, Tamagayatsuri and non superior weeds competed

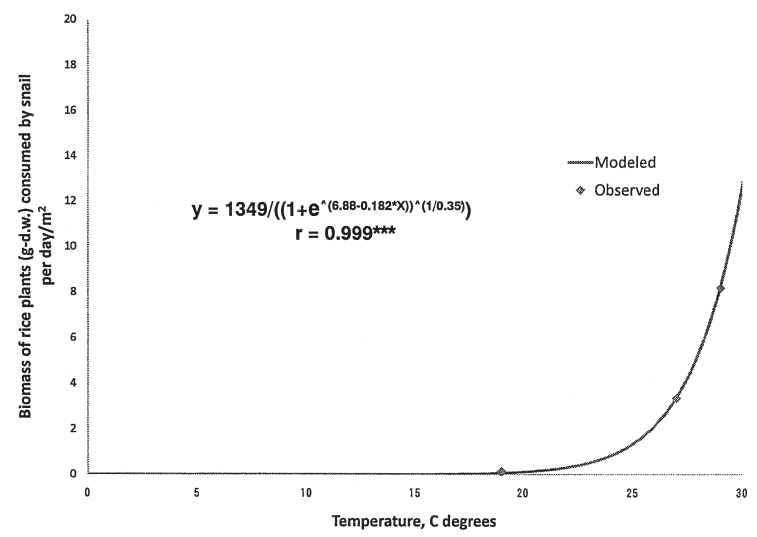

Fig. 6. Dried biomass of rice plants (g-d.w.) consumed by a snail (34 mm of shell height and $9 \mathrm{~g}$ of weight) per day as a function to the water temperature and related to a coefficient of depth water rate $\left(W_{d}\right)$ of 0.7 , abundance of snails per square meter $\left(A_{p}\right)$ and maximum consumption $\left(C_{\max }\right)$ of 0.3 g-d.w. per day by snail.

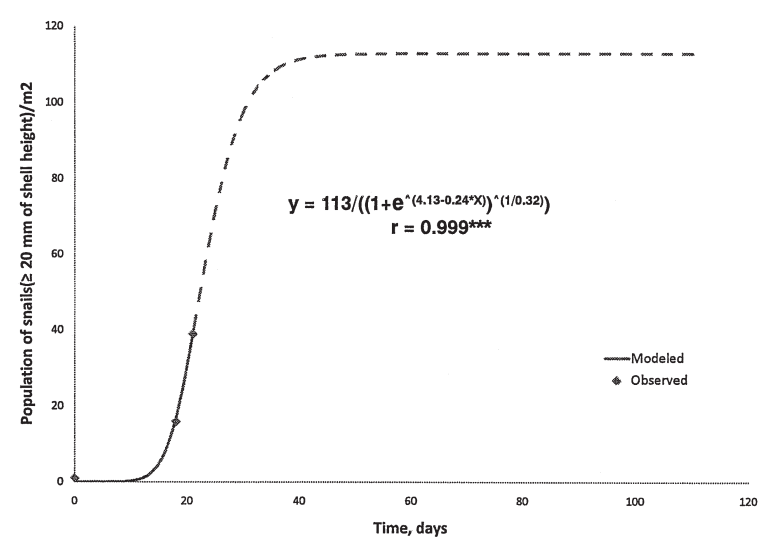

Fig. 7. Population of snails ( $\geq 20 \mathrm{~mm}$ of shell height) per square meter observed in rice cropping season of 2008 and modeled by Richards's equation. 


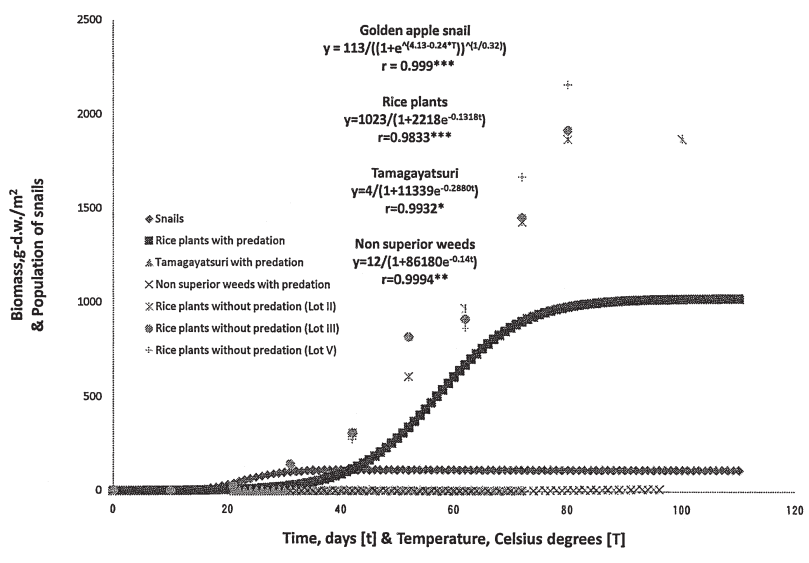

Fig. 8. Curves of biomasses of rice plants, Tamagayatsuri and non superior weeds per square meter predicted by Verhulst logistic model population of snails ( $\geq 20 \mathrm{~mm}$ of shell height) per $\mathrm{m}^{2}$ fitted by Richards's equation in paddy during crop season, 2008. Rice plants, Tamagayatsuri and non superior weeds were predated by snail at $30 \%, 80 \%$ and $80 \%$ respectively in these prediction equations.

among them and were predated by snails at 30\%, 80\% and $80 \%$ respectively in the prediction equations shown in Figure 8.

\section{DISCUSSION AND CONCLUSION}

The severe predation of rice plants by snails occurred from June 20th of July 30th. In this critical stage the rice plants had heights from 12 to $400 \mathrm{~mm}$. The water temperatures ranged from 19 to 31 Celsius degrees. Those temperatures were suitable for the maximum activity of snails.

The sigmoid of Viggs and Burley and equation of Richards had predicted significantly the temperature response function and predation rate respectively. The Richards's equation also modeled the populations significantly during the critical stage of rice crop season.

\section{REFERENCES}

Gotelli, N. J. 1998 A Primer of Ecology, 2nd edition. Sinauer Associates, Inc. Sunderland, MA, USA, pp. 100-124

Holling, C. S. 1959 The components of predation as revealed by a study of small mammal predation of the European Pine Sawfly. Canadian Entomologist, 91: 293-320

Joshi R. C., Dela Cruz M. S., Martin A. R., Duca A. V. and E. C. Martin 2002 Relation of golden apple snail size to rice seedling damage in transplanted and direct-seeded rice cultivation. Int. Rice Res. Notes 27: 37-38.

Keeling, M. J., H. B. Wilson and S. W. Pacala 2002 Deterministic limits to stochastic spatial models of natural enemies. The American Naturalist, 159: 57-80

Lotka, A. J. 1925 Elements of Physical Biology. Williams and Willkins Co, Baltimore, USA

Luna Maldonado, A. I. and K. Nakaji 2008 Development of an Intelligent Robot for an Agricultural Production EcosystemNew Concept of Robot and Dynamics of a Golden Apple Snail in Paddy-. Journal of the Faculty of Agriculture, Kyushu University, 53: 115-119

Luna Maldonado, A. I., Y. Yamaguchi, M. Tuda and K. Nakaji 2008 a Development of an Intelligent Robot for an Agricultural Production Ecosystem (II) - Modeling of the Competition between rice plants and weeds -. Journal of the Faculty of Agriculture, Kyushu University, 53: 511-516

Luna Maldonado, A. I., Y. Yamaguchi, M. Tuda and K. Nakaji 2008b Development of an Intelligent Robot for an Agricultura Production Ecosystem (III) - Modeling of the Predation of Rice Plants and Weeds by Golden Apple Snail-. Journal of the Faculty of Agriculture, Kyushu University, 53: 517-521

Luna Maldonado, A. I., Y. Yamaguchi and K. Nakaji 2009c Development of an Intelligent Robot for an Agricultural Production Ecosystem (IV) - Experiments on Growth and Competition of Rice Plants against Weeds-. Journal of the Faculty of Agriculture, Kyushu University, 54: 231-234

Richards, F. J. 1959 A flexible growth function for empirical use. Journal of Experimental Botany, 24: 190-300

Teo, S. S. 2004 Biology of the golden apple snail, Pomacea canaliculata (Lamarck 1822), with emphasis on responses to certain environmental conditions in Sabah, Malasya. Molluscan Research, 24: 139-148

Vandermeer J. H. 1990 Elementary Mathematical Ecology, Krieger Publishing Company, Malabar, Florida, USA, pp. 1-67

Vigg, S., C. Burley, D. Ward, C. Mallette, S. Smith, and M. Zimmerman. 1990 Development of a system-wide predator control program: stepwise implementation of a predation index, predator control fisheries, and evaluation plan in the Columbia River Basin. Annual report 1990. Portland, OR: U.S. Department of Energy, Bonneville Power Administration, Division of Fish and Wildlife

Volterra V. 1926 Variazioni e fluttuazioni del numero d'individui in specie animali conviventi. Memorie della $R$. Accademia Nazionale dei Lincei, 54: 31-113 